\title{
HIGH THROUGHPUT GENERATED MICRO-AGGREGATES OF CHONDROCYTES STIMULATE CARTILAGE FORMATION IN VITRO AND IN VIVO
}

\author{
L.S. Moreira Teixeira. ${ }^{1,}$, J.C.H. Leijten ${ }^{1, \S}$, J. Sobral ${ }^{2}$, R. Jin ${ }^{3}$, A.A. van Apeldoorn${ }^{1}$, J. Feijen ${ }^{3}$, \\ C. van Blitterswijk ${ }^{2}$, P.J. Dijkstra" ${ }^{1,3}$ and M Karperien ${ }^{1, *}$
}

\begin{abstract}
${ }^{1}$ Department of Developmental BioEngineering, MIRA Institute for Biomedical Technology and Technical Medicine, Faculty of Science and Technology, University of Twente, Enschede, The Netherlands.

${ }^{2}$ Department of Tissue Regeneration, MIRA Institute for Biomedical Technology and Technical Medicine,

Faculty of Science and Technology, University of Twente, Enschede, The Netherlands.

${ }^{3}$ Department of Polymer Chemistry and Biomaterials, MIRA Institute for Biomedical Technology and Technical

Medicine, Faculty of Science and Technology, University of Twente, Enschede, The Netherlands.

${ }^{\S}$ Both authors contributed equally
\end{abstract}

\begin{abstract}
Cell-based cartilage repair strategies such as matrixinduced autologous chondrocyte implantation (MACI) could be improved by enhancing cell performance. We hypothesised that micro-aggregates of chondrocytes generated in high-throughput prior to implantation in a defect could stimulate cartilaginous matrix deposition and remodelling. To address this issue, we designed a micromould to enable controlled high-throughput formation of micro-aggregates. Morphology, stability, gene expression profiles and chondrogenic potential of micro-aggregates of human and bovine chondrocytes were evaluated and compared to single-cells cultured in micro-wells and in 3D after encapsulation in Dextran-Tyramine (Dex-TA) hydrogels in vitro and in vivo. We successfully formed micro-aggregates of human and bovine chondrocytes with highly controlled size, stability and viability within 24 hours. Micro-aggregates of 100 cells presented a superior balance in Collagen type I and Collagen type II gene expression over single cells and micro-aggregates of 50 and 200 cells. Matrix metalloproteinases 1, 9 and 13 mRNA levels were decreased in micro-aggregates compared to singlecells. Histological and biochemical analysis demonstrated enhanced matrix deposition in constructs seeded with micro-aggregates cultured in vitro and in vivo, compared to single-cell seeded constructs. Whole genome microarray analysis and single gene expression profiles using human chondrocytes confirmed increased expression of cartilagerelated genes when chondrocytes were cultured in microaggregates. In conclusion, we succeeded in controlled highthroughput formation of micro-aggregates of chondrocytes. Compared to single cell-seeded constructs, seeding of constructs with micro-aggregates greatly improved neocartilage formation. Therefore, micro-aggregation prior to chondrocyte implantation in current MACI procedures, may effectively accelerate hyaline cartilage formation.
\end{abstract}

Keywords: Aggregation; chondrocyte; chondrogenesis; biomaterial; cartilage repair; cell therapy.
*Address for correspondence:

Marcel Karperien

Department of Developmental BioEngineering

MIRA Institute for Biomedical Technology and Technical

Medicine

Faculty of Science and Technology

University of Twente, Enschede, The Netherlands.

Telephone Number: +31 (0) 534893323 /3400

FAX Number: +31 (0) 534892150

E-mail: h.b.j.karperien@utwente.nl

\section{Introduction}

Articular cartilage has a limited capacity for regeneration due to its avascular nature and deficiency on migrating or responding undifferentiated cell populations (Buckwalter and Mankin, 1998; Jones and Peterson, 2006). Arthroplasty can be successfully used to treat degenerative joints at end stage disease. Due to the limited life-span of the prosthesis and the complications with revision surgery, this treatment option is less suited for young active patients with focal defects. Non-arthroplastic options include debridement, micro-fracture, osteochondral grafting, autologous chondrocyte implantation (ACI) or matrixassisted autologous chondrocyte implantation (MACI). Both ACI and MACI are the most technically advanced procedures, representing promising treatment modalities, yet still with associated limitations (Jones and Peterson, 2006; Vavken and Samartzis, 2010; Batty et al., 2011). The limited availability of autologous chondrocytes and their tendency to lose their phenotype during the required 2-D expansion phase to obtain sufficient cells for implantation are major drawback of these techniques. The current challenge to improve the therapeutic outcome of these techniques is to develop strategies that induce maximal cartilaginous matrix deposition per chondrocyte, avoiding the cost-prohibitive use of growth factors.

A myriad of biomaterials that provide an artificial extracellular matrix compatible with homogenous distribution of single cells or micro-aggregates are currently available for cartilage tissue regeneration strategies (Woodfield et al., 2002; Wolf et al., 2008). Among the classes of biomaterials, hydrogels of natural polymers show promising features as defect filling scaffolds due to their similarity to the native cartilaginous 
extracellular matrix. In situ gelating injectable hydrogels have deserved much attention since they can be applied in a minimally invasive procedure and allow the possibility of cell incorporation during the gelation reaction (Kuo et al., 2006). Recently, we have developed a novel injectable enzymatically cross-linkable Dextran-Tyramine hydrogel (Dex-TA, $14 \mathrm{kDa}, \mathrm{DS}=15$ ). This fast gelating hydrogel is fully compatible with cell viability and has shown high potential for cartilage regeneration (Jin et al., 2007; Jin et al., 2010). Moreover, this hydrogels allows for in situ immobilisation of the cartilage at the defect site (Moreira Teixeira et al., 2012).

Not only the biomaterial design can be tuned to support cartilage regeneration, but also the selection of the cell source and cell seeding methods are of equal paramount importance. Aggregation of chondrocytes is a well-studied phenomenon that enhances the chondrogenic phenotype. Traditionally it is employed by generating micromasses of 200,000-500,000 chondrocytes. More recently, smaller aggregates are formed by culturing chondrocytes on agarose coated surfaces or micrometric patterns (Hamilton et al., 2006; Wolf et al., 2008). However, such methods of aggregation are uncontrollable and yield insufficient amounts of aggregates needed for clinical application. In consequence, aggregation of chondrocytes prior to implantation has not been implemented in current MACI procedures.

To overcome these limitations, we designed a platform that enables the formation of highly controlled chondrocyte aggregates in a high-throughput fashion, which can be combined with the enzymatically cross-linkable Dextrantyramine hydrogel. We evaluated the effect of chondrocyte micro-aggregation in vitro and in vivo. We demonstrated that micro-aggregation enhanced sensitivity to chondrogenic stimuli and decreased the expression of catabolic factors, resulting in higher accumulation of cartilaginous matrix. We postulate that controllable high-throughput platforms such as described in this study enables the feasibility of the use of micro-aggregated chondrocytes in cell based cartilage repair strategies such as ACI or MACI. This might allow for improved therapeutic outcome by significantly boosting neocartilage formation.

\section{Materials and Methods}

\section{Tissue source and preparation}

The use of human material was approved by a local medical ethical committee. OA cartilage was obtained from the knee joints of adult patients suffering from late stage OA undergoing an arthroplasty, after informed consent. Bovine cartilage was obtained from a local abattoir. Human and bovine primary chondrocytes were isolated from knee articular cartilage by collagenase digestion and cultured in chondrocyte expansion medium composed of Dulbecco's modified Eagle's medium high glucose (Invitrogen, Carlsbad, CA, USA), $10 \%$ foetal bovine serum (Cambrex, East Rutherford, NJ, USA), 100 $\mathrm{U} / \mathrm{mL}$ penicillin (Invitrogen), $100 \mathrm{mg} / \mathrm{mL}$ streptomycin
(Invitrogen), $0.2 \mathrm{mM}$ ascorbic acid (ASAP; Sigma-Aldrich, St. Louis, MO, USA), $0.1 \mathrm{mM}$ non-essential amino acids (Sigma-Aldrich), and $0.4 \mathrm{mM}$ proline (Sigma-Aldrich).

Tissue samples were fixated, dehydrated and embedded in paraffin. Macroscopically OA cartilage was used to evaluate morphological features. Sections of $5 \mu \mathrm{m}$ were collected and stained with haematoxylin-eosin (H\&E) for further evaluation using light microscopy.

\section{Mould design and micro-aggregate formation}

Stainless steel moulds were machined using a femtosecond pulsed laser system to produce a negative replica of the micro-wells. The depth of the mould was designed to be 200-300 $\mu \mathrm{m}$. The spacing between wells was 250 $\mu \mathrm{m}$. To produce agarose micro-wells, autoclave-sterilised powder Ultrapure ${ }^{\mathrm{TM}}$ Agarose (Invitrogen) was dissolved by heating in sterilised PBS at $2 \% \mathrm{w} / \mathrm{v}$ and added drop by drop into a previously sterilised O-Ring (with an area of $1.9 \mathrm{~cm}^{2}$ ) placed on top of the micro-fabricated stainless steel mould. After solidifying, the gels were separated from the mould and transferred into 24-well culture plates. Each well of the 24-well culture plate contained $4 \times 10^{3}$ micro-wells (Fig. 1).

Different cell densities (20, 50, 100, 200, 300 and 500 cells per micro-well) were used to study the effect of cell number on the form and size of the micro-aggregates. Appropriate cell densities were seeded into each well of the 24 -well plates containing $4 \times 10^{3}$ agarose micro-wells to obtain micro-aggregates of 50, 100 and 200 cells. Microaggregation was induced by gravity after seeding a single cell suspension on top of the micro-wells. Both expansion and chondrocyte differentiation medium (DMEM with $0.1 \mu \mathrm{m}$ dexamethasone (Sigma-Aldrich), $100 \mu \mathrm{g} / \mathrm{mL}$ sodium pyruvate (Sigma-Aldrich), $0.2 \mathrm{~mm}$ ascorbic acid, $50 \mathrm{mg} / \mathrm{mL}$ insulin-transferrin-selenite (ITS +1 , SigmaAldrich), $100 \mathrm{U} / \mathrm{mL}$ penicillin, $100 \mu \mathrm{g} / \mathrm{mL}$ streptomycin, $10 \mathrm{ng} / \mathrm{mL}$ transforming growth factor $\beta 3$ (TGF- $\beta 3$, Invitrogen)) were used. The micro-aggregates were kept in culture in the micro-wells in a humidified atmosphere containing $5 \% \mathrm{CO}_{2}$ at $37{ }^{\circ} \mathrm{C}$ up to $7 \mathrm{~d}$. Single cells were cultured in $2 \mathrm{D}$ on tissue culture plastic at the same cell density. Microscopic images were collected at several time points and morphometric analysis of the micro-aggregates was performed using ImageJ software.

\section{Dextran-Tyramine hydrogels (Dex-TA)}

Dex-TA with a degree of substitution of 15 , defined as the number of tyramine (TA) moieties per 100 anhydroglucose (AHG) units in dextran, was prepared as described previously (Jin et al., 2007; Jin et al., 2010). Bovine chondrocytes (passage 2) either as micro-aggregates or as single cell suspension at a concentration of $10 \times 10^{6}$ cells per $\mathrm{mL}$ were mixed with the polymer solution. The hydrogel precursor/cell suspension was mixed with $\mathrm{H}_{2} \mathrm{O}_{2}$ (hydrogen peroxide, Sigma-Aldrich) and horseradish peroxidase (HRP type VI, 298 purpurogallin unit/mg solid, SigmaAldrich) and gelation occurred within one minute (the final concentration of Dex-TA was $10 \% \mathrm{wt}$ ). The amount of HRP used was fixed at $0.25 \mathrm{mg}$ per mmol of TA moieties and the molar ratio of $\mathrm{H}_{2} \mathrm{O}_{2} / \mathrm{TA}$ was $0.20(\mathrm{~mol} / \mathrm{mol})$. 

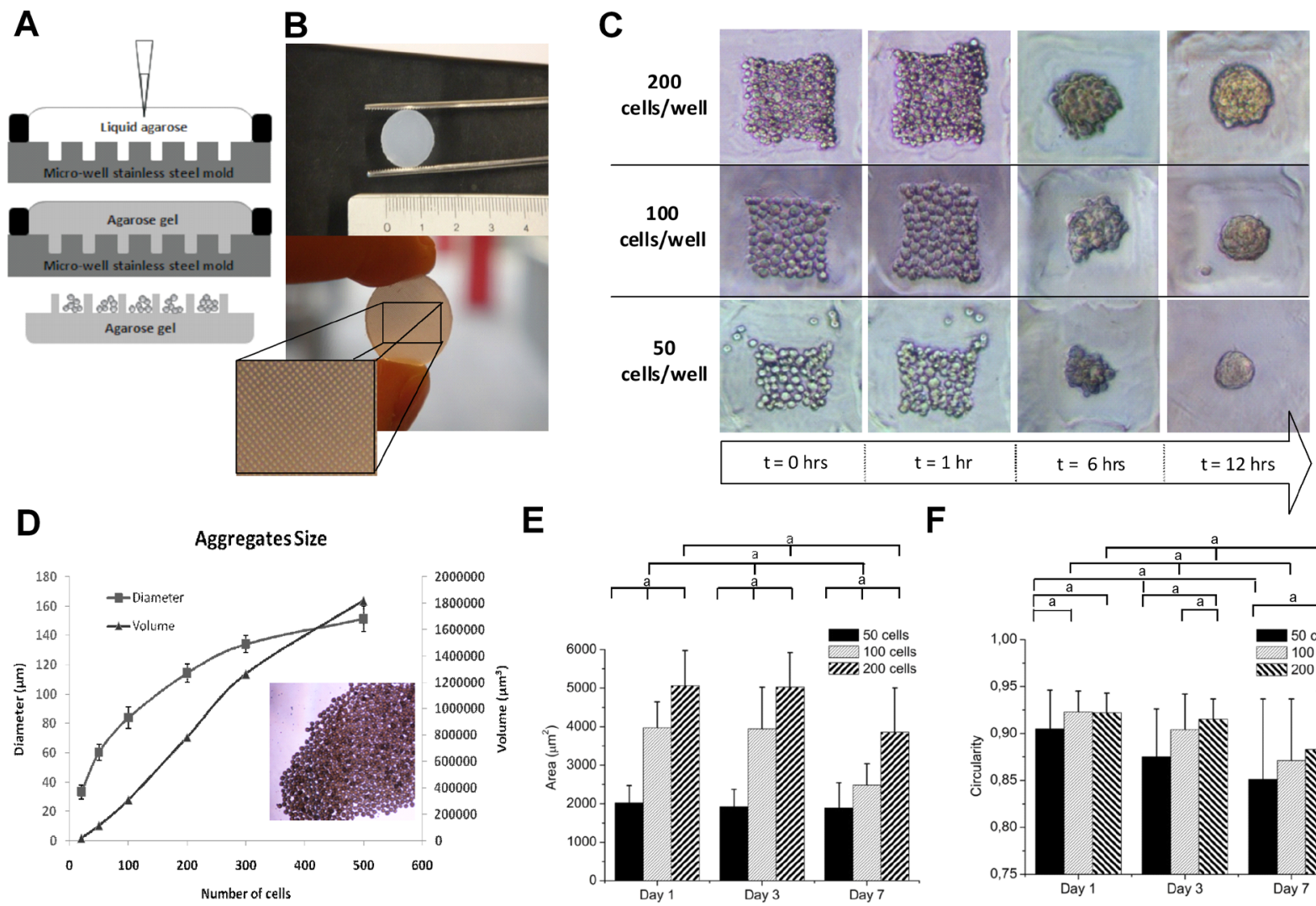

E
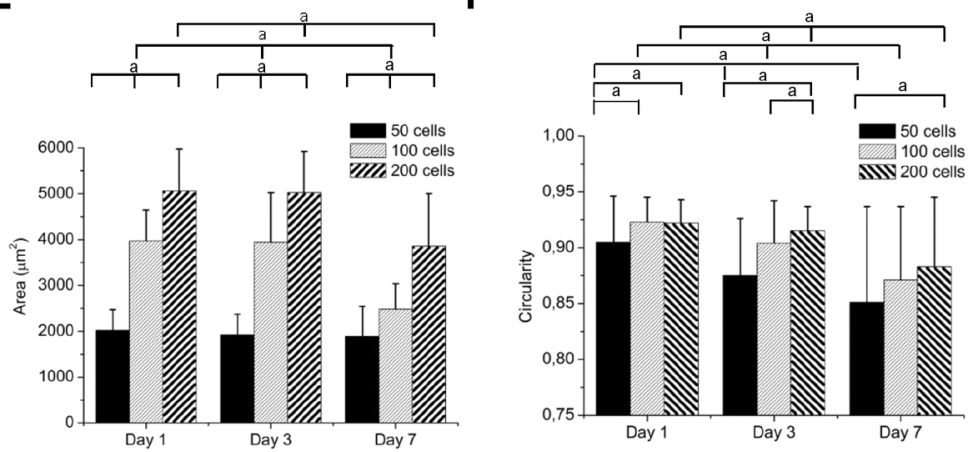

Fig. 1. High-throughput formation of chondrocyte micro-aggregates. (A) Schematic representation of the micro-well technique for the formation of aggregates from single cell suspensions. A stainless steel mould was used to form micro-wells in agarose chips. (B) Each agarose chip contains 4 x 10 $0^{3}$ micro-wells. (C) Pictures at specific time points during aggregate formation. Each well of a 24 wells plate containing an agarose micro-well chip was seeded with the appropriate number of bovine chondrocytes to obtain micro aggregates of 50, 100 or 200 cells. Aggregation started to occur approximately $6 \mathrm{~h}$ after seeding. After $12 \mathrm{~h}$, the aggregates had acquired a spherical shape, independently of aggregate size. (D) Correlation between the number of chondrocytes per micro-well and the diameter $(\mu \mathrm{m})$ and the volume $\left(\mu \mathrm{m}^{3}\right)$ of the obtained aggregates after $12 \mathrm{~h}$. Each data point represents the measurement of minimally 50 micro-aggregates. At the lower right side of the graphic, aggregates obtained after flushing off the agarose chips are shown. (E) Micro-aggregate area $\left(\mu \mathrm{m}^{2}\right)$ slightly decreased over time most notably in aggregates bigger than 100 cells. Each data point represents the measurement of minimally 50 aggregates (F) Measurement of circularity of micro aggregates over time demonstrated a decrease in average circularity and an increase in spread. A perfect circle has a value of 1 . Each data point represents the measurement of about 50 micro-aggregates. Error bars represent means $\pm \mathrm{SD}$.

\section{Metabolic activity and chondrocyte viability}

Quantification of glucose consumption, as well as lactate and ammonia production by chondrocyte micro-aggregates of 100 cells on micro-wells and single cells cultured for $7 \mathrm{~d}$ in differentiation medium, was determined using a Vitros DT60 II medium analyser (Ortho-Clinical Diagnostics, Tilburg, The Netherlands). The viability of the chondrocytes incorporated in the hydrogels either as single cells or as micro aggregates was assessed by a Livedead assay. At day 7 and 14, the hydrogel constructs were rinsed with PBS and stained with calcein AM/ethidium homodimer using the Live-dead assay Kit (Invitrogen), according to the manufacturers' instructions and evaluated using fluorescence microscopy. Living cells fluoresce green and the nuclei of dead cells red.

\section{In vivo implantation}

Chondrocyte micro-aggregates of 100 cells were allowed to form for $24 \mathrm{~h}$ in expansion medium. Afterwards, the aggregates were flushed out of the micro-wells and mixed with polymer precursor, as described above. Samples of each hydrogel type, containing either single cells or aggregates of 100 cells were cultured in vitro and at pre-determined time-points analysed for cell viability, metabolic activity, matrix biosynthesis and gene expression analysis or were surgically implanted subcutaneously in 8-weeks-old nude male mice (NMRI-Nude, Harlan, Indianapolis, IN, USA) for a period of 2 or 4 weeks. The operative procedure and the care of the mice were performed under the regulation of the Central Laboratory Animal Institute (GDL), Utrecht University (Utrecht, The Netherlands). The study was approved by a local animal ethical committee.

\section{Histological analysis}

At 14 and $21 \mathrm{~d}$, hydrogel constructs seeded with single cells or aggregates of 100 cells and cultured in differentiation medium were fixed in $10 \%$ buffered formalin for $1 \mathrm{~h}$. 
Table 1. Forward and reverse primers for bovine chondrocytes.

Collal 5'-GCGGCTACGACTTGAGCTTC-3', 5'-CACGGTCACGGACCACATTG-3'; Col2al 5' - ATCAACGGTGGCTTCCACT-3', 5'-TTCGTGCAGCCATCCTTCAG-3'; Colloal 5'-CATGCTGCCACAAACAGC-3', 5'-TGGATGGTGGGCCTTTTA-3'; Acan 5'-GACCAGAAGCTGTGCGAGGA-3', 5'-GCCAGATCATCACCACACAG-3'; Sox9 5'-CCATTCAGGCCCACTACAAG-3', 5'-CAGGGTTTCCGTCTGACATC-3'; Mmp 1 5'- CTTTGATGGACCTGGTGGAAAC-3', 5'-AAATGAGCGTCTCCTCCGATAC-3'; Mmp3 5'-TTAGAGAACATGGGGACTTTTTG-3', 5'- CGGGTTCGGGAGGCACAG-3'; Mmp 9 5'-CGCCACCACCGCCAACTACG-3', 5'-GGGGGTGCTCCTCTGTGAATCTGT-3'; Mmp 13 5'-ATTCTTCTGGCGGCTGCATCC-3', 5'-AGGCGGCATCAATACGGTTGG-3'; Gapdh 5'-GCCATCACTGCCACCCAGAA-3', 5'-GCGGCAGGTCAGATCCACAA-3'.

Table 2. Forward and reverse primers for human chondrocytes.

COL2A1 5'-AAGTCCAGGCTGTCCAGGGATG-3', 5'-CGTCCAGATGACCTTCCTACG- -3'; ACAN 5'-GGCAGCGTGATCCTTACC-3', 5'-GGCCTCTCCAGTCTCATTCTC-3'; SOX9 5'-TGGGCAAGCTCTGGAGACTTC-3', 5'-ATCCGGGTGGTCCTTCTTGTG-3'; COMP 5'-AAGAACGACGACCAAAAGGAC-3', 5'-CATCCCCTATACCATCGCCA-3'; GAPDH 5'-CGCTCTCTGCTCCTCCTGTT-3', 5'-CCATGGTGTCTGAGCGATGT-3'.

For the in vivo experiments, the samples were explanted after 2 and 4 weeks and allowed to fixate in $10 \%$ buffered formalin overnight at $4{ }^{\circ} \mathrm{C}$. After embedding the samples in cryomatrix (Cryomatrix, Shandon/Thermo Fisher Scientific, Waltham, MA, USA), a cryo-microtome (Leica, Wetzlar, Germany) was used to collect $10 \mu \mathrm{m}$ sections onto gold-coated slides. The cryomatrix was washed off the slides by incubation in distilled water for $10 \mathrm{~min}$. Afterwards, three histological stainings were performed: Picrosirius Red staining for visualisation of total collagen (processed according to the manufacturer's instructions (Polysciences, Warrington, PA, USA) and both Toluidine blue (Fluka/Sigma-Aldrich, $0.1 \%$ in deionised water, 10 min incubation) and Safranin O (Sigma-Aldrich, $0.1 \%$ in deionised water, $5 \mathrm{~min}$ incubation) for glycosaminoglycans (GAGs) visualisation. The slides were then washed, dehydrated, mounted and analysed using a bright field microscope (Nikon, Tokyo, Japan; Eclipse E400).

\section{Glycosaminoglycan content}

Sulphated glycosaminoglycan content per cell was determined on micro-aggregates of 100 cells and single cells incorporated in Dex-TA hydrogels, as described above, and cultured in differentiation medium for 14 and $21 \mathrm{~d}$. Bovine primary chondrocytes (P2) and three different human chondrocyte donors (P2) were used. After the selected time points, the samples were washed with PBS and frozen at $-80{ }^{\circ} \mathrm{C}$ until further processing. The constructs were digested in proteinase-K (Sigma) at $56{ }^{\circ} \mathrm{C}$ ( $>16 \mathrm{~h}$ ). Quantification of total DNA was performed using the PicoGreen assay kit (Invitrogen) using a fluorescent plate reader (Perkin-Elmer, Waltham, MA, USA). The amount of GAG was determined using the sulphated glycosaminoglycan assay (Blyscan, Biocolor, Country Antrim, UK), according to manufacturer's instructions. The obtained values were normalised to the DNA content and expressed as sGAG/DNA $(\mu \mathrm{g} / \mu \mathrm{g})$. Statistical significance was determined by one-way ANOVA with Tukey's posthoc analysis.

\section{Whole genome gene expression microarray analysis}

Whole genome gene expression microarray analysis was performed on micro-aggregates of 100 cells and single cells incorporated in Dex-TA hydrogels, as described above, and cultured in differentiation medium for $7 \mathrm{~d}$. Three different human chondrocyte donors were used. NuGEN (San Carlos, CA, USA) Ovation PicoSL WTA System kit followed by Encore BiotinIL module was used to generate biotinylate single stranded cDNA starting from $50 \mathrm{ng}$ total RNA. $750 \mathrm{ng}$ of the obtained samples was hybridised onto the Illumina (San Diego, CA, USA) HumanHT-12 v4 Expression BeadChips. Samples were scanned using the Illumina iScan array scanner. Gene expression profiling was performed using llumina's Genomestudio v. 2010.3 software with the default settings advised by Illumina. Data was normalised by applying quantile normalisation on the raw fluorescence intensity values. Differential gene expression was analysed using the commercial software package Genespring, version 11.5.1. (Agilent Technologies, Santa Clara, CA, USA). Three-dimensional Principal Component Analysis (PCA) was used to demonstrate the differences in global gene expression between single cells and micro-aggregates. Hierarchical clustering was used to group all samples on similarity. Changes of gene expression in annotated canonical pathways and bio-functions were visualised using ingenuity pathway analysis software (Ingenuity Systems, Redwood City, CA, USA). Search Tool for the Retrieval of Interacting Genes/Proteins (STRING) was used to investigate the predicted gene-gene interaction network (Szklarczyk et al., 2011). Markov clustering algorithm was used to identify interacting clusters of genes and encoded proteins within the microarray dataset.

\section{Real time PCR analysis}

Hydrogel/cell constructs cultured for either 7, 14 or 21 $\mathrm{d}$ in differentiation medium were washed with PBS and lysed using Trizol reagent (Invitrogen). Total RNA was isolated using the Nucleospin RNA II kit (Bioke, Leiden, 


\section{A Chondrocyte expansion medium COL2A1}

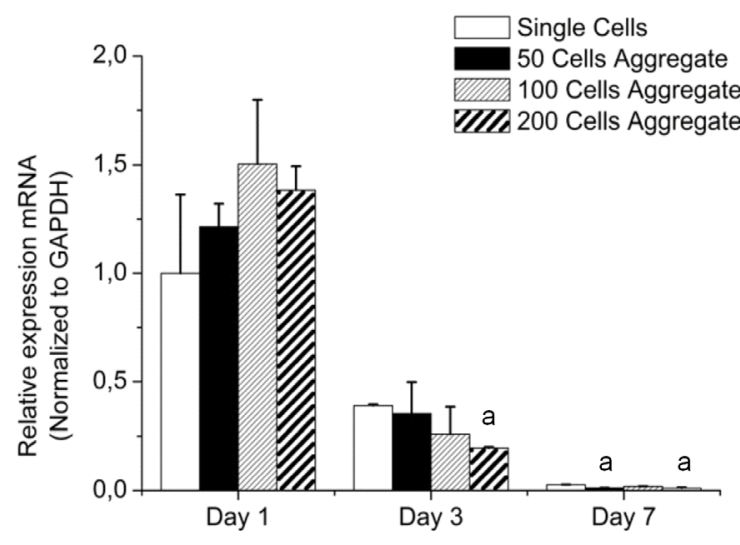

ACAN
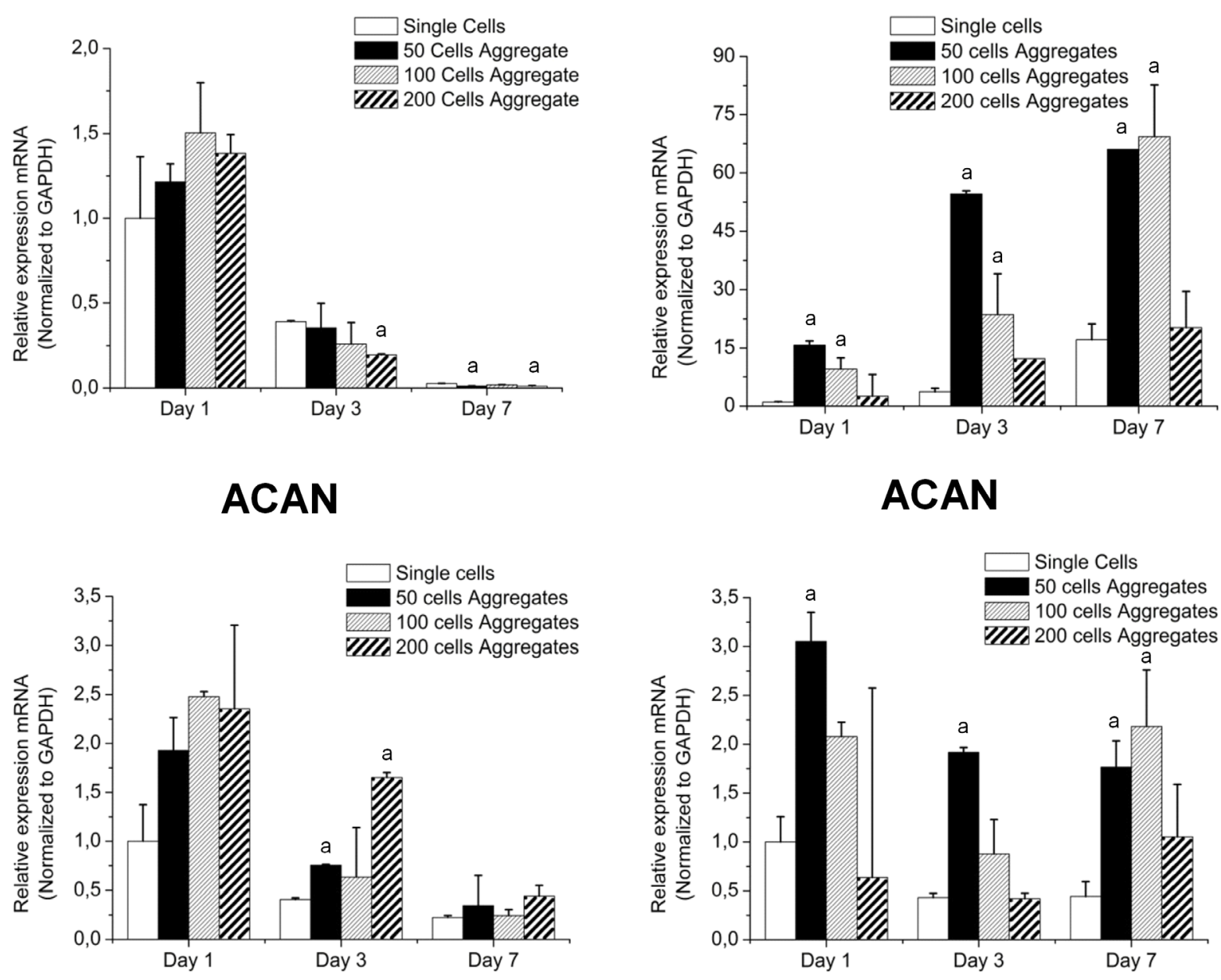

ACAN

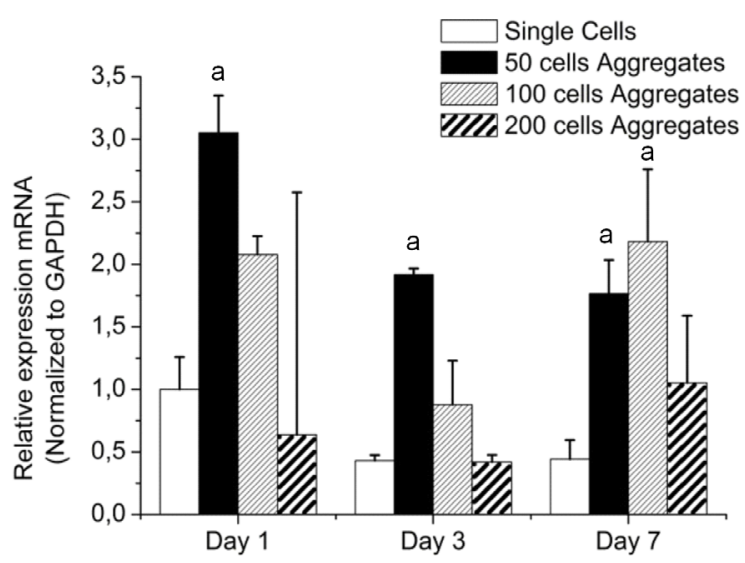

Fig. 2. Micro-aggregation enhances collagen type II and aggrecan expression. (A) qPCR analysis of collagen type II (Col2al) and aggrecan (Acan) gene expression at day 1,3 and 7 of culture in chondrocyte expansion medium. Equal amounts of cells were cultured in micro-aggregates of 50,100 and 200 bovine chondrocytes and compared with single cells cultured in a 2-D system. At day 7, no changes were observed between the different culture methods. (B) qPCR analysis of Col2al and Acan gene expression was evaluated at day 1,3 and 7 of culture in chondrogenic conditions. Micro-aggregated cell clusters of 50, 100 and 200 cells were compared with single cells cultured in a 2-D system. Col2al and Acan expression was potently stimulated by culturing the cells in micro-aggregates of 50 and 100 cells. Error bars represent means $\pm \mathrm{SD}(n=3$ /condition).

The Netherlands) according to manufacturer's instructions. The RNA yields were determined using the Nanodrop2000 (ND-1000 Spectrophotometer, Isogen LifeScience, De Meern, The Netherlands). Subsequently, cDNA was synthesised using the iScript Kit (BioRad, Hercules, CA, USA) according to the manufacturer's recommendations. Expression levels of individual genes were analysed by quantitative PCR (MiQ, BioRad), using forward and reverse primers for bovine chondrocytes according to Table 1 , and for human chondrocytes according to Table 2. Gene expression was normalised to the expression of Gapdh or $G A P D H$ respectively.

\section{Statistical analysis}

Statistical differences between two groups were analysed using the Student's $t$-test or by one-way ANOVA. Statistical significance was set to a $p$ value $\leq 0.05$ and indicated with an ${ }^{\text {a }}$. Results are presented as mean \pm standard deviation.

\section{Results}

High-throughput generated chondrocyte microaggregates resemble chondrocyte clusters in $\mathrm{OA}$ Micro-fabricated moulds were used as a tool to generate chips of identically shaped micro-wells in agarose. The procedure is outlined in Fig. 1A. These chips were placed in 24-well plates and subsequently used to generate microaggregates similar to the ones observed in OA cartilage for further studies in high-throughput (Fig. 1B). Shortly after seeding of a single cell suspension, gravitational 
A

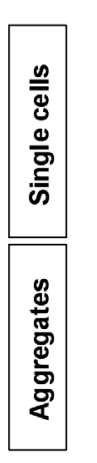

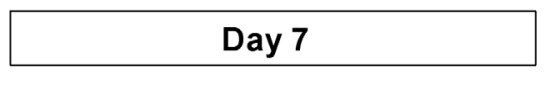

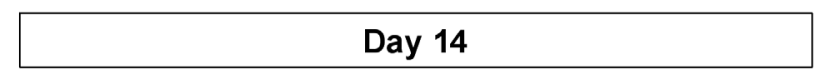

B
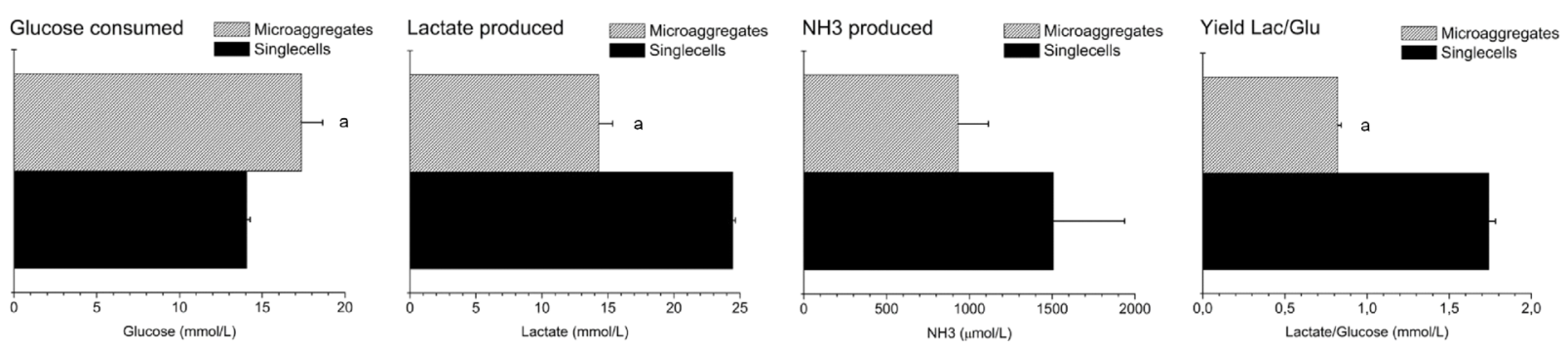

Fig. 3. Micro-aggregation increases metabolic activity. (A) Equal numbers of bovine chondrocytes, either as microaggregates or as single cells, were embedded in an in situ gelating Dex-TA hydrogel. After 7 and $14 \mathrm{~d}$ of culture, a viability assay was performed in which living cells were shown in green and dead cells in red. Incorporation of cells in the hydrogels did not affect viability nor did micro-aggregation. Clusters retained their spherical shape over time. Scale bars $=200 \mu \mathrm{m}$. (B) Glucose consumption and ammonia and lactate production were quantified after $7 \mathrm{~d}$ of culture of equal cell numbers of 100 cell micro-aggregates of bovine chondrocytes on agarose chips or as single cells in $2 \mathrm{D}$. The ratio between lactate production and glucose consumption is represented in the lower right graphic. The clear difference between both culture systems was strongly suggestive for a shift in metabolic activity. Error bars represent means $\pm \mathrm{SD}$ ( $n=3 /$ condition).

force resulted in the concentration of chondrocytes at the bottom of the micro-wells. The chondrocytes contracted to a spherical aggregate thereby increasing intercellular contacts and minimising free energy (Fig. 1C). To study the effect of cell number in aggregation speed and stability of the micro-aggregates of bovine chondrocytes, pictures of the aggregates in the micro-wells were collected at different time points after seeding. The number of cells affected the speed of aggregate formation. We observed that lower cell densities demanded longer aggregation time, most likely due to limited contact opportunities (Fig. 1C). After 24 $\mathrm{h}$, the aggregates were collected by flushing the non-cell adherent agarose chips with medium. The percentage of aggregate recovery was $96.6 \%$. The aggregates could withstand centrifugation and resuspension in medium, as shown in Fig. 1D. Analysis of a correlation between cell seeding density, aggregate diameter and volume, demonstrated a linear correlation between seeding density and the aggregate volume assuming a spherical conformation (Fig. 1D).

To evaluate aggregate stability after formation, the area and circularity of aggregates composed of 50,100 and 200 cells were analysed after 1, 3 and $7 \mathrm{~d}$ in culture. The area and circularity of the aggregates are represented in Figs.
$1 \mathrm{E}$ and $\mathrm{F}$. As expected, the area of the aggregates decreased slightly over time due to condensation. The circularity of the aggregates provided information about stability and uniformity of the aggregates. Higher deviations in circularity were observed at later stages of culture and particularly in aggregates with lower cell densities. In subsequent experiments, aggregates were collected 24 $\mathrm{h}$ after seeding, since this time point was sufficient to obtain stable micro-aggregates starting from single cell suspensions. Furthermore, extension of this culture time tended to result in migration of the micro-aggregates to neighbouring wells and their subsequent merger suggesting a chemotactic attraction between the aggregates. This process resulted in an increased heterogeneity in size.

\section{Micro-aggregation stimulates cartilage matrix formation}

Gene expression of Aggrecan and Collagen type II was evaluated using bovine chondrocytes. Aggregates with densities of 50, 100 and 200 cells were cultured in the micro-wells and compared with single cells cultured in 2D using similar cell numbers. Figure 2A shows that aggregates cultured in expansion medium tended to slightly up-regulate the expression of both collagen type II and 
A

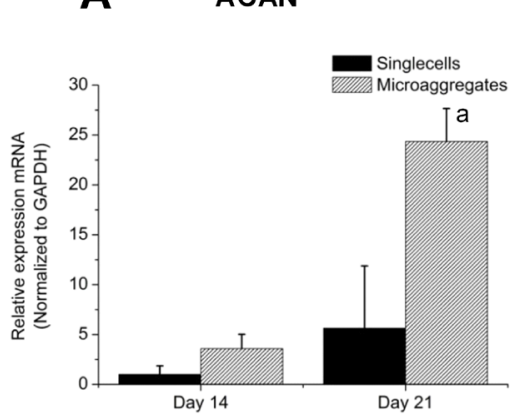

D $\quad$ COL1

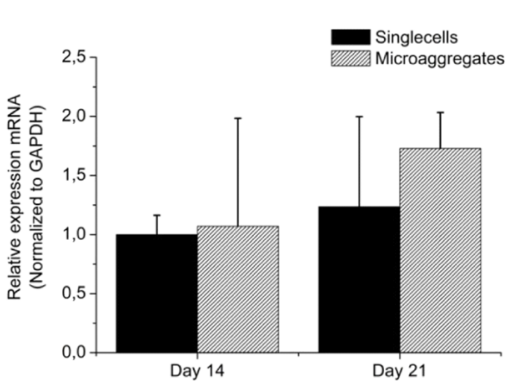

B

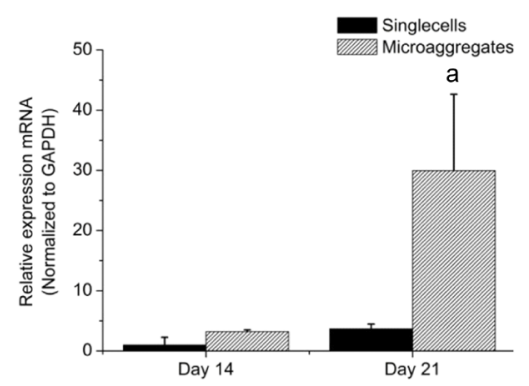

E
C

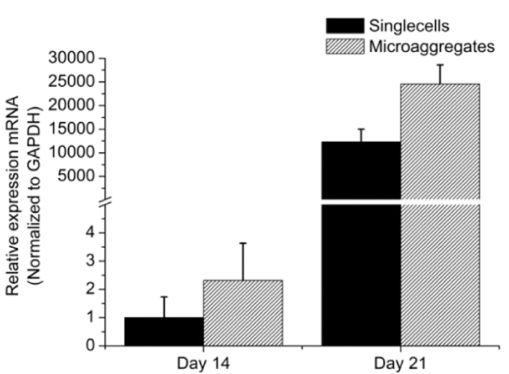

$\mathbf{F}$

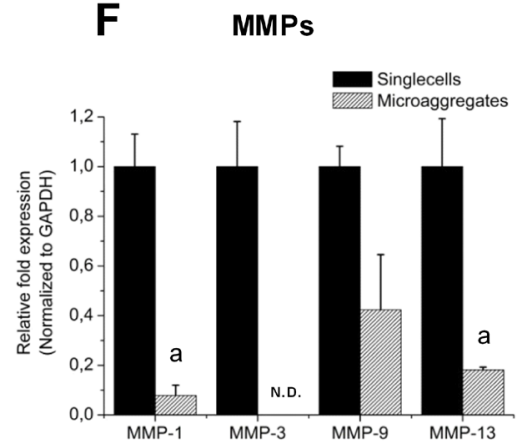

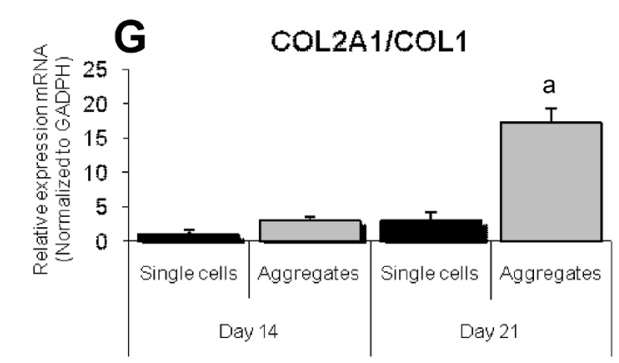

Fig. 4. Micro-aggregation prior to seeding in hydrogels stimulates cartilage matrix gene expression. Relative mRNA levels for Aggrecan (Acan) (A), collagen type II (Col2a1) (B), Sox9 (Sox9) (C), collagen type I (Col1) (D) and Collagen type X (Col10) (E), expressed by single bovine chondrocytes or micro-aggregated cell clusters incorporated into Dex-TA hydrogels, after 14 and $21 \mathrm{~d}$ in culture. Similar cell numbers were seeded in each construct. Relative mRNA levels for metalloproteinases (MMPs) 1, 3, 9 and 13 (F), expressed by single chondrocytes or microaggregated cell clusters incorporated into Dex-TA hydrogels, after $21 \mathrm{~d}$ in culture. (G) Col2a1/Coll ratio to elucidate chondrogenic phenotype development. Error bars represent means $\pm \mathrm{SD}$ ( $n=3 /$ condition).

aggrecan, compared to single cells cultured in 2D. Figure $2 \mathrm{~B}$ shows that, when the aggregates were chondrogenically stimulated with TGF- $\beta 3$, the gene expression of collagen type II and aggrecan significantly increased in microaggregates of 50 and 100 cells, compared to single cells and to aggregates of 200 cells. Overall, gene expression analysis demonstrated that micro-aggregates behaved similarly to single cells when cultured without stimulation. However, when the micro-aggregates were exposed to chondrogenic conditions containing stimulatory molecules alike found in native cartilage, cartilage matrix formation was significantly enhanced in aggregates of 50 and 100 cells with a less pronounced effect in aggregates of 200 cells. Given the higher stability of aggregates of 100 cells compared to aggregates of 50 cells, these cell clusters were selected for further experimentations.

Micro-aggregated bovine cell clusters remain viable after embedding in a hydrogel

We studied the effect of micro-aggregation on cell metabolism in comparison to equal numbers of single cells after embedding of the cells in a dextran based hydrogel. As shown in Fig. 3A, both single cells and microaggregates were uniformly distributed in the hydrogel and remained viable. The integrity of the micro-aggregates did not change over culture time. Micro-aggregated cell clusters were metabolically more active than single cell seeded constructs (Fig. 3B). Micro-aggregates laden constructs had a significantly higher consumption of glucose and production of both lactate and ammonia. This suggested that aggregation of chondrocytes stimulated cell metabolism presumably due to higher cell-cell contacts. During glycolysis, oxidation of one molecule of glucose leads to two molecules of pyruvate and, subsequently, by anaerobic respiration, to two molecules of lactate. This expected 2:1 ratio of lactate:glucose was observed when single cells were cultured in the hydrogels. When cells were cultured in aggregates this ratio dropped to $1: 1$. This significant difference was suggestive for a metabolic shift suggesting that a part of the glucose may be used in biosynthesis of extracellular matrix molecules rather than energy consumption. 

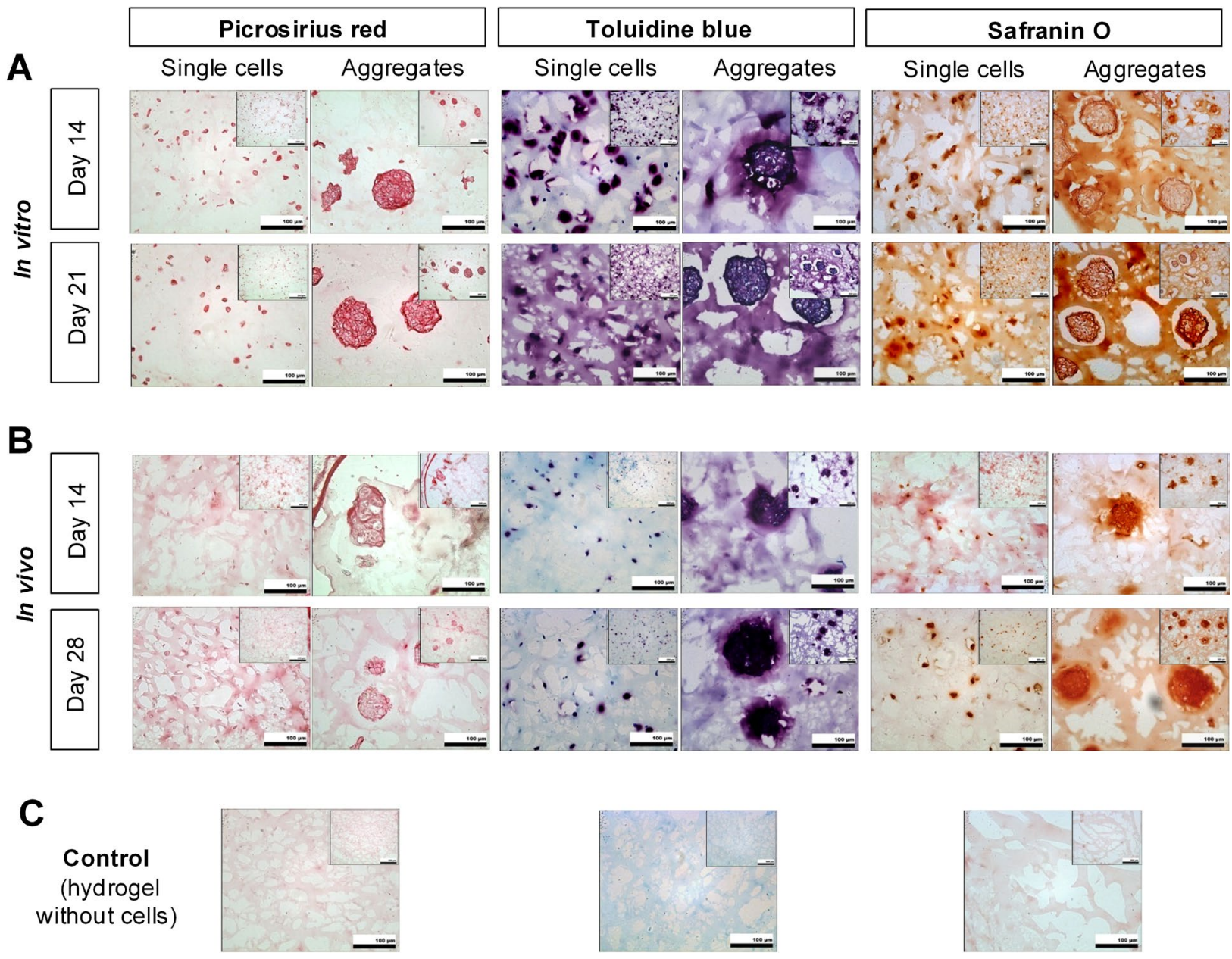

Fig. 5. Micro-aggregation resulted in superior matrix production both in vitro and in vivo. (A) Histological evaluation of in vitro cultured hydrogels seeded with equal bovine chondrocyte numbers either as single cells or as micro-aggregates of 100 cells, for 14 and $21 \mathrm{~d}$. Picrosirius red staining was performed to visualise total collagen content (red/pink colour). Both Toluidine blue (purple colour) and Safranin O (red/orange colour) stainings were performed to visualise glycosaminoglycans deposition. A more intense staining was observed in constructs seeded with micro-aggregates indicative for higher matrix production. (B) Histological evaluation of hydrogel constructs with encapsulated single cells or micro-aggregates of 100 cells implanted subcutaneously in nude mice for 2 and 4 weeks ( $n=6$ mice per time point). Hydrogels with encapsulated micro aggregates showed more cartilage matrix. (C) Histological stainings of a representative control sample, consisting of the hydrogel without cells. Scale bars $=100 \mu \mathrm{m}$.

\section{Bovine and human cell cluster formation enhanced cartilage matrix deposition}

Micro-aggregates of 100 cells or single cells suspensions of bovine chondrocytes with equal cell numbers were incorporated in a Dex-TA hydrogel and cultured in chondrocyte differentiation medium for 14 and $21 \mathrm{~d}$. The relative fold expressions of chondrogenic related genes such as aggrecan, collagen type II and Sox 9 were up-regulated in hydrogels containing micro-aggregates compared to constructs seeded with equal numbers of single cells (Fig. 4A to C). Figure 4-G shows that the ratio of collagen type II and collagen type I is improved in constructs seeded with micro-aggregates. Over time, these differences became more pronounced. Additionally, no significant differences in gene expression of both collagen type I or X were observed between single cells and microaggregates, at any time point (Fig. 4D and E).

The expression of several MMPS was analysed after $21 \mathrm{~d}$ in culture to evaluate the effect of cell clustering of bovine chondrocytes. As shown in Fig. 4F, a decrease in the expression of MMP-1, MMP-9 and MMP-13 was observed in hydrogels cultured with micro-aggregated cells. The expression of MMP-3 was not detected in constructs seeded with micro-aggregates.

The gene expression analysis was corroborated by histology (Fig. 5A,B) using bovine chondrocytes. Picrosirius red staining was more intense in hydrogels containing aggregated cells, suggesting the presence of more collagens (Fig. 5-A). The staining did not further increase by extending culture time from 14 to $21 \mathrm{~d}$. The presence of GAGs was visualised by Toluidine blue and Safranin O staining (Fig. 5A). Both stainings were more intense in hydrogels seeded with micro-aggregates compared to single cell seeded constructs. This difference was more striking at day 21. Additionally, mainly at day 14, a gradient of GAGs diffusing out of the micro-aggregates and into the hydrogel was visible. Similar results, and even more pronounced, were obtained 2 and 4 weeks after 


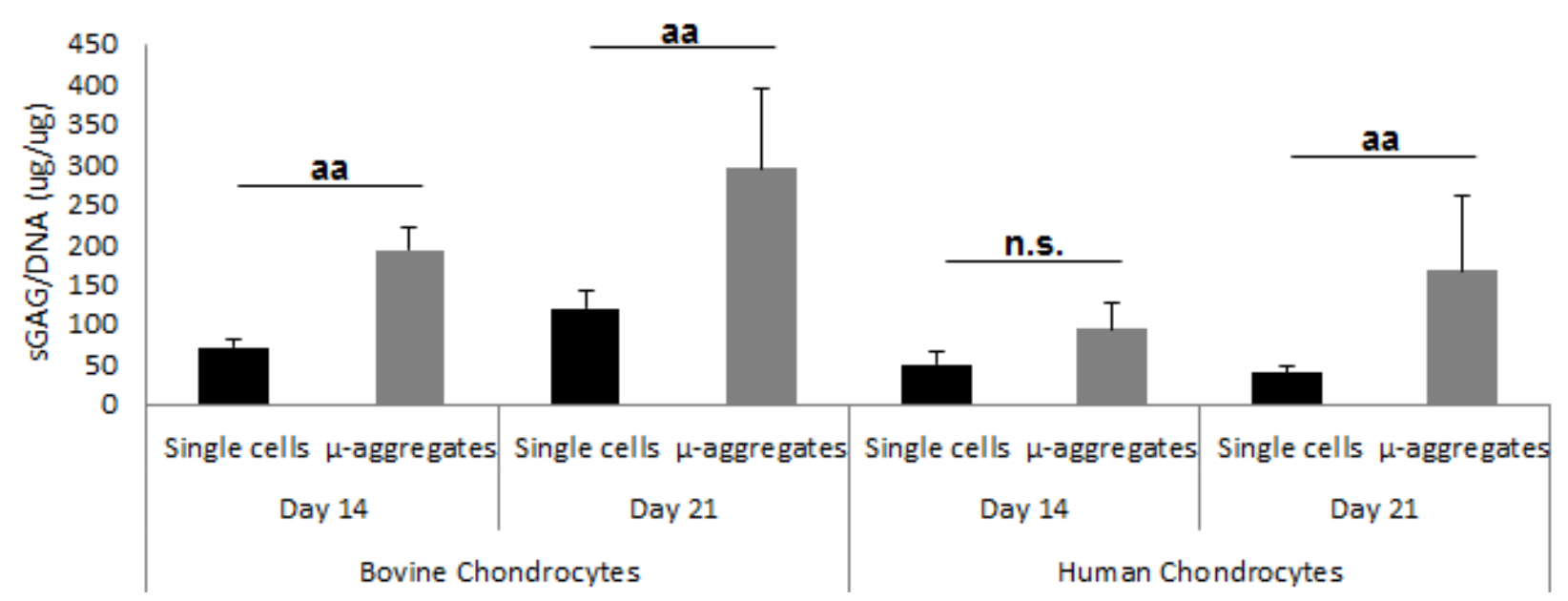

Fig. 6. Glycosaminoglycan content of micro-aggregates doubled compared single cells. Quantification of GAG content normalised to the amount of DNA of micro-aggregates of chondrocytes or of single cells incorporated into Dex-TA hydrogels, after 14 and $21 \mathrm{~d}$ in culture. The amount of matrix per cell was addressed using bovine and 3 donors of human chondrocytes, revealing a clear increase in micro-aggregated cell clusters, when compared to single cells, for both cell sources and time points analysed. Error bars represent means $\pm \operatorname{SD}$ ( $n=3$ to $6 /$ condition).

A

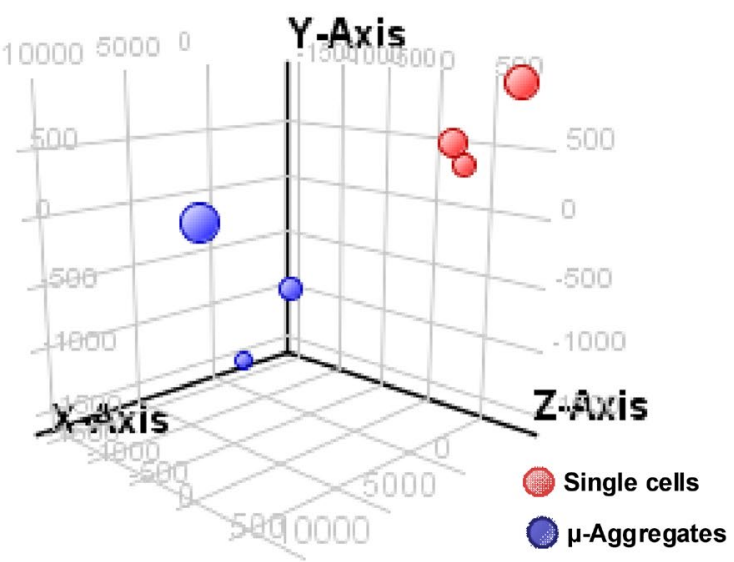

C

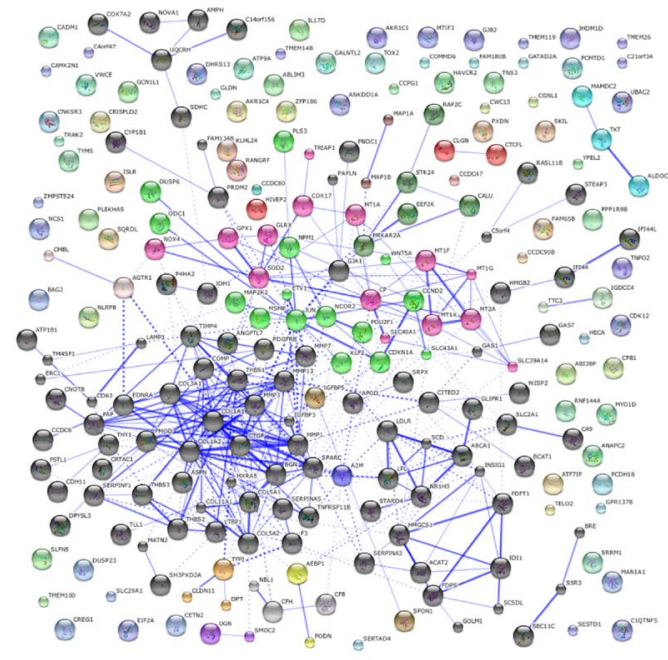

B

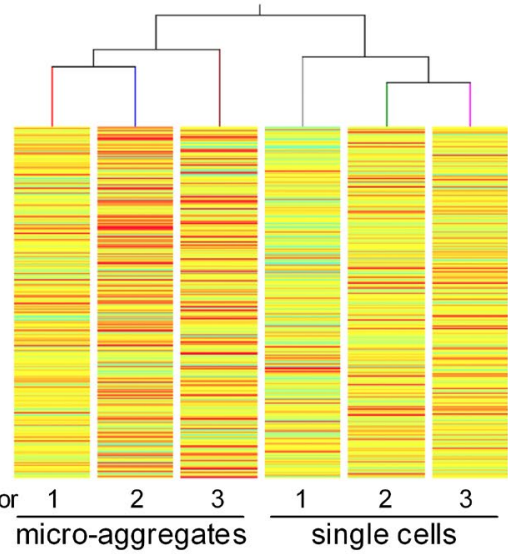

D

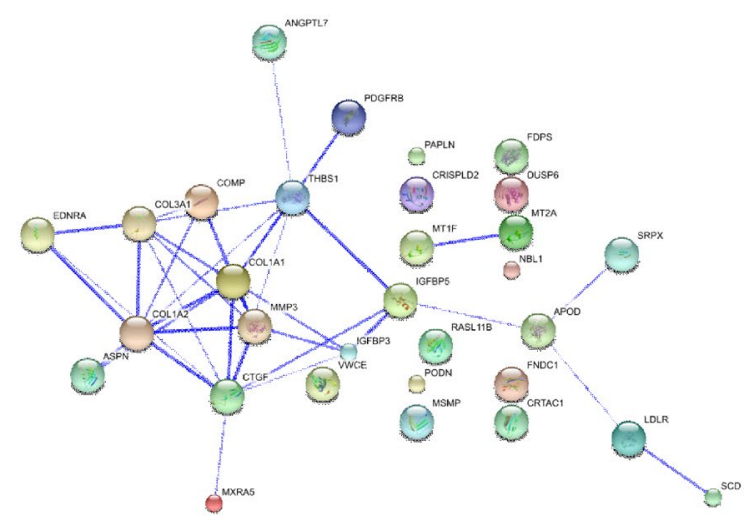

Fig. 7. Whole genome gene expression analysis of micro-aggregates vs. single cells. (A) 3-D PCA plot of all detected probes of micro-aggregates (blue spheres) of human chondrocytes or of single cells (red spheres). (B) Hierarchical clustering of all significant differentially regulated genes between micro-aggregates (agg) and single cell chondrocytes (ss). (C) and (D) Gene and protein interaction networks of all selected significant differentially expressed genes or (D) and the subset of the higher differentially expressed genes. 
A

\begin{tabular}{|l|}
\hline Assigned Function \\
\hline Cellular Assembly and Organization \\
\hline Cellular Function and Maintenance \\
\hline Organ Development \\
\hline Cellular Growth and Proliferation \\
\hline Connective Tissue Development and Function \\
\hline Skeletal and Muscular System Development and Function \\
\hline Tissue Morphology \\
\hline Cell Death \\
\hline Amino Acid Metabolism \\
\hline Organ Morphology \\
\hline
\end{tabular}
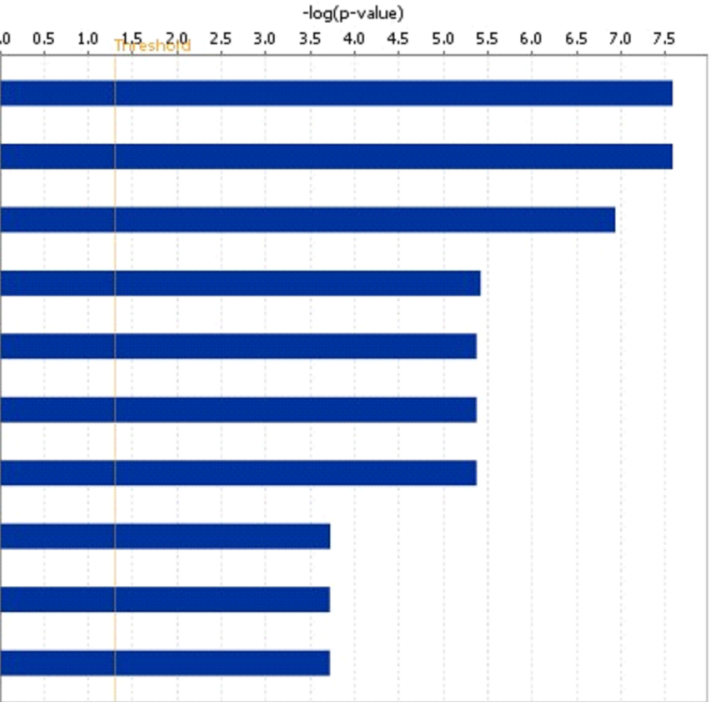

B

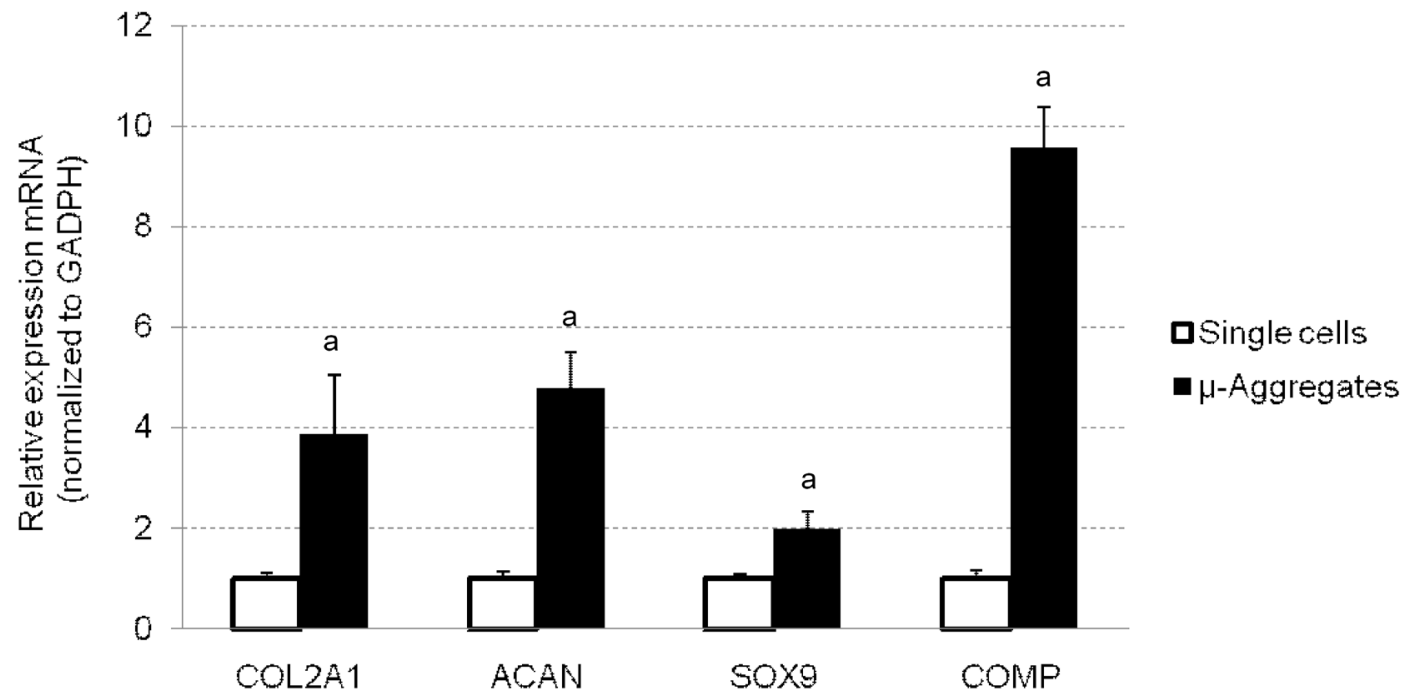

Fig. 8. Differentially regulated bio-function list and qPCR validation of microarray data. (A) Differentially regulated bio-functions of micro-aggregates vs. single cells based on Ingenuity's pathway analysis of whole genome gene expression microarrays. (B) qPCR validation of micro-array data. COL2A1, ACAN, SOX9 and COMP showed upregulation in the micro-aggregated cells by microarray and qPCR. Error bars represent means $\pm \operatorname{SD}(n=6 /$ condition).

subcutaneous implantation of the cell seeded hydrogel constructs in nude mice (Fig. 5B).

The increase of GAG content in the micro-aggregated chondrocytes inferred by the histological evaluation was confirmed by the GAG/DNA quantification (Fig. 6). The amount of sGAG normalised to the DNA content was determined using human or bovine chondrocytes incorporated into Dex-TA hydrogels after 14 and $21 \mathrm{~d}$ in culture. The formation of human chondrocyte clusters occurs similarly to bovine chondrocyte cell clusters and their incorporation in Dex-TA hydrogels was equally efficient. The amount of GAG/DNA of micro-aggregated bovine chondrocytes doubled compared to single cells already at day 14 . The same remarkable difference was also observed for both human and bovine chondrocytes at day 21 of culture.
Microarray analysis confirmed increased expression of cartilage-related genes in human chondrocyte clusters

Whole genome gene expression profiling was used on human chondrocytes to validate our experimental model in a human system and to obtain a deeper understanding of the transcriptional effects of chondrocyte microaggregation. Gene expression profiles on constructs laden with identical cell numbers either as single cells or in micro-aggregates were distinct as demonstrated by 3D principal component analysis (Fig. 7A). Moreover, hierarchical cluster analysis demonstrated the presence of two main clusters: chondrocytes cultured as microaggregates or as single cells. Gene and protein interactions analysis of the differentially regulated genes between single cells and micro-aggregates revealed one major central hub 
(Fig. 7C). Interestingly, this intricate network contained the most highly differentially regulated genes such as connective tissue growth factor (CTGF) and extracellular matrix-related genes like COL3A1, COMP and $M M P-3$ (Fig. 7D). Indeed, bio-function analysis demonstrated significant differences in processes like 'cellular assembly and organisation', 'cellular functions and maintenance', 'connective tissue development and function' and 'skeletal and muscular system development and function' (Fig. 8A). Gene expression patterns of 4 genes of interest were validated using qPCR (Fig. 8B). The selected genes were COL2A1, ACAN, SOX9 and COMP, which are cartilage-related genes that were up-regulated in the microaggregates. This data showed striking similarity with the experiments using bovine chondrocytes, suggesting that the effect of micro-aggregation on cartilage matrix formation is species-independent.

\section{Discussion}

In this study, we developed an in vitro micro cell-cluster platform that enabled the high-throughput formation of highly controllable micro-aggregates that can be harvested without enzymatic digestion or mechanical shearing. This allowed us to study the effect of micro-aggregation of chondrocytes on cartilage matrix formation and their potential as therapeutic cell source when combined with an in situ gelating injectable biomaterial. We demonstrated that formation of micro-aggregates resulted in enhanced cartilage matrix production and decreased MMPs transcription.

Cartilage repair strategies based on autologous chondrocyte implantation relies on in vitro expansion to obtain sufficient cells. Although this method results in more cells, the chondrocyte perform inferior as they underwent dedifferentiation (Kuo et al., 2006). Studies focusing on the self-aggregation potential of chondrocytes and its use for elastic cartilage reconstruction have been hampered due the problem of dedifferentiation and scarcity of starting material (de Chalain et al., 1999; Fukuda et al., 2006; Strobel et al., 2010). They have shown that by embedding aggregates in moulded hydrogels, chondronlike clusters are formed and, thus, dedifferentiation of the chondrocytes is avoided, or at least delayed. In this study, we demonstrated that we can boost the chondrogenic potential of these expanded cells solely by pre-aggregating the chondrocytes before implantation by using a fully controlled high throughput platform. Moreover, we demonstrated that the aggregate size is relevant to the chondrogenic stimulus.

Due to the cartilage's inherent low capacity to selfrepair, the retention of cells in cell-based cartilage repair strategies at the defect site is of the highest importance. We have chosen enzymatically cross-linkable self-attaching dextran-tyramine hydrogels to evaluate whether seeding constructs with micro-aggregated cells rather than with single cells has a beneficial effect on cartilage matrix formation. Prior to incorporation of the micro-aggregates in the injectable Dex-TA hydrogels, different culture times and cell densities were evaluated to select the optimal micro-aggregate size. Interestingly, we observed that larger micro-aggregates, such as 200 cells, were out-performed by smaller micro-aggregates, composed of 50 and 100 cells. Additionally, higher micro-aggregate stability was achieved in shorter formation time when aggregating 50 to 100 cells compared to 200 cells. After $3 \mathrm{~d}$ in culture, the micro-aggregates tended to merge due to cell migration, most likely facilitated by the increasing matrix that surrounded the aggregates. The merging of aggregates with increasing culture time has been previously reported (de Chalain et al., 1999; Furukawa et al., 2003; Hamilton et al., 2006). Most probably, this process is driven by chemotactic factors secreted by the chondrocytes (DeLise et al., 2000; Martinez et al., 2010). Based on stability and formation characteristics, as well as expression of a chondrogenic gene profile, we selected aggregates of 100 cells as the optimal size for further experiments.

Micro-aggregates of 100 cells seeded in Dex-TA hydrogels proved to be viable and retained their integrity. Moreover, the aggregates could be easily uniformly distributed in the gel. Interestingly, when the bovine chondrocytes were cultured in the aggregated form within hydrogels, a change in cell metabolism was observed. This might be due to a metabolic shift from a catabolic glycolysis pathway in single cell constructs to a more anabolic pathway in constructs seeded with aggregated cells. As cause or consequence of these events, glucose might have been directed to a greater extent to biosynthesis and, thus contributing to enhanced matrix production in micro-aggregates seeded constructs. Indeed this was supported by increased matrix deposition in hydrogels seeded with micro-aggregates. Likewise, the increase in biosynthesis in early cartilage lesions has been previously reported (Poole et al., 1993; Aurich et al., 2005). Comparable shifts from catabolic to the anabolic responses have been recently reported to occur by varying the exposure of chondrocytes to different oxygen percentages (Strobel et al., 2010). Lower oxygen percentages, similar to physiological concentrations, significantly enhanced the chondrogenic capacity of chondrocytes cultured in micromass pellets. The enhanced chondrogenic behaviour of the micro-aggregates might be at least in part explained by a relatively lower exposure to oxygen of cells in microaggregates compared to single cells in 2-D. However, other possibilities such as concentrating effects of both secreted soluble factors and extracellular matrix molecules cannot be excluded. Regardless of the cause, micro-aggregates of 100 cells outperformed single cells and showed therefore a greater potential for cell-based cartilage repair strategies.

Interestingly, morphometric analysis and gene expression profiles suggested that without addition of chondrogenic stimuli, both single bovine cells and microaggregates behaved similarly suggesting that aggregation itself does not change cell behaviour. However, when stimulated with a chondrogenic stimulus, such as TGF- $\beta 3$, micro-aggregated cells showed a very distinct response from single cells. A strong additional effect on cartilage matrix formation was obtained when cells were cultured in a micro-aggregated form.

Chondrocyte clusters are a histological hallmark of OA, the most prevalent form of degenerative joint diseases (Lotz 
et al., 2010). Interestingly, it has recently been suggested that this clustering of chondrocytes are a self-reparative response of the cartilage, but experimental evidence is lacking (Lee et al., 2000). The formation of chondrocyte aggregates or clusters in OA occurs by increased cell proliferation or active movement of the chondrocytes (Kouri et al., 1998; Pfander et al., 2001; McGlashan et al., 2008). Chondrocyte clusters can be composed by more than 20 cells and are localised in the proximity of fissures in the upper cartilage layers (Lotz et al., 2010; Schumacher et al., 2002). Although previous studies have investigated the effect of chondrocyte clustering on cartilage formation, these aggregates were formed either in insufficient quantity, with improper or poorly controlled size ranges, or attached to scaffold sheets (de Chalain et al., 1999; Kelm and Fussenegger, 2004; Penick et al., 2005; Fukuda et al., 2006; Hamilton et al., 2006; Khademhosseini et al., 2006). In contrast, the high throughput method described in this study allowed us to address this issue more systematically. Our data substantiates the hypothesis that micro-clusters of chondrocytes, such as observed in OA, may indeed be part of a regenerative response. To our knowledge, we are the first to address the function of micro-clusters by an experimental approach showing potent stimulation of cartilage matrix formation. Since we have not studied the function of micro-aggregates in an OA-like environment, e.g. in the presence of inflammatory cytokines, we cannot exclude that the OA-environment alters the behaviour of the micro-aggregates. Using our model, the effect of various factors involved in OA can be easily addressed in a high-throughput approach. In addition, the potential to form these micro-aggregates in high-throughput potentially allows us to translate this method to a clinical application.

Considering the difference in expression ratio of collagen type II and collagen type X between clusters of bovine chondrocytes, it might be worthwhile to explore differential seeding of constructs with micro-aggregates of various sizes to reconstruct the zonal organisation of cartilage. The role of micro-scale organisation in a cartilage model has previously been investigated using cell clusters obtained by photo-immobilisation of single cells in a hydrogel as described by Albrecht et al. (Albrecht et al., 2006). In contrast to our study, no effect on cartilage matrix formation was observed. This difference might be explained by the cell-cell contact achieved with our approach of cell cluster formation, compared to the cell density approach in which cells are in close proximity, yet a couple of $\mu \mathrm{m}$ still apart. The two distinct outcomes suggest that close cell-cell contact and contraction forces during condensation of cell clusters strongly affect cell behaviour (DeLise et al., 2000; Griffith and Swartz, 2006). Thus, the system reported by Albrecht et al. resembled more a 2D cell system within a hydrogel support. Our approach has the advantage of first enabling aggregate condensation while still retaining the possibility of combining these aggregates with an injectable hydrogel. Moreover, micro-aggregation prior to implantation in current ACI or MACI protocols might be highly beneficial for the clinical outcome. Thus, the extra simple step suggested herein might lead to a great improvement of current protocols.
Previous related studies have investigated the differences in gene expression using only a selection of genes. Consequently, the mechanism of action of the increased cartilage formation after micro-aggregation has remained largely unknown. To the best of our knowledge, this is the first comprehensive study that included a whole genome gene expression analysis elucidating gene regulatory networks involved in human chondrocyte microaggregation. Our data suggested a central role for CTGF (also known as CCN2). It has been shown that CTGF is a potent mediator of chondrogenesis and is involved in the cell cycle (Maeda et al., 2009). Furthermore, CTGF is an established TGF $\beta$ target gene and mediates many of TGF $\beta$ 's effects (Song et al., 2007). Indeed, the major changes in bio-functions were related to cellular function, proliferation and connective and skeletal tissue development. Moreover, our data demonstrated that the transcriptional effects of chondrocyte micro-aggregation are conserved between tested species.

Collectively, our data demonstrate that chondrocyte micro-aggregation prior to seeding of tissue engineered constructs has a beneficial effect on cartilage matrix formation compared to single cell cultures. Our experimental approach mimicking cell clusters, such as found in OA and other cartilage related diseases caused by chemical or mechanical injury, suggests that these clusters may indeed be part of an innate self-regenerative response of cartilage. Using our approach, it is possible to produce in high-throughput micro-aggregates with specific cell densities, using a simple and reproducible method. These micro-aggregates can be successfully incorporated into injectable in situ forming hydrogels, without affecting cell viability and the aggregates' spherical shape, while boosting cartilage formation compared to single cellseeded constructs. Therefore, high-throughput formation of micro-aggregates prior to chondrocyte implantation in current ACI and MACI protocols may improve and accelerate hyaline cartilage formation.

\section{Acknowledgements}

The authors gratefully acknowledge the support of the DPTE (Dutch Program for Tissue Engineering) and the TeRM Smart Mix Program of the Netherlands Ministry of Economic Affairs and the Netherlands Ministry of Education, Culture and Science. The authors report that no competing financial interests exist.

\section{References}

Albrecht DR, Underhill GH, Wassermann TB, Sah RL, Bhatia SN (2006) Probing the role of multicellular organization in three-dimensional microenvironments. Nat Methods 3: 369-375.

Aurich M, Squires GR, Reiner A, Mollenhauer JA, Kuettner KE, Poole AR, Cole AA (2005) Differential matrix degradation and turnover in early cartilage lesions of human knee and ankle joints. Arthritis Rheum 52: 112119. 
Batty L, Dance S, Bajaj S, Cole BJ (2011) Autologous chondrocyte implantation: an overview of technique and outcomes. ANZ J Surg 81: 18-25.

Buckwalter JA, Mankin HJ (1998) Articular cartilage repair and transplantation. Arthritis Rheum 41: 1331-1342.

de Chalain T, Phillips JH, HinekA (1999) Bioengineering of elastic cartilage with aggregated porcine and human auricular chondrocytes and hydrogels containing alginate, collagen, and kappa-elastin. J Biomed Mater Res 44: 280 288.

DeLise AM, Fischer L, Tuan RS (2000) Cellular interactions and signaling in cartilage development. Osteoarthritis Cartilage 8: 309-334.

Fukuda J, Khademhosseini A, Yeo Y, Yang X, Yeh J, Eng G, Blumling J, Wang CF, Kohane DS, Langer R (2006) Micromolding of photocrosslinkable chitosan hydrogel for spheroid microarray and co-cultures. Biomaterials 27: 5259-5267.

Furukawa KS, Suenaga H, Toita K, Numata A, Tanaka J, Ushida T, Sakai Y, Tateishi T (2003) Rapid and largescale formation of chondrocyte aggregates by rotational culture. Cell Transplant 12: 475-479.

Griffith LG, Swartz MA (2006) Capturing complex $3 \mathrm{D}$ tissue physiology in vitro. Nat Rev Mol Cell Biol 7: 211-224.

Hamilton DW, Riehle MO, Monaghan W, Curtis AS (2006) Chondrocyte aggregation on micrometric surface topography: a time-lapse study. Tissue Eng 12: 189-199.

Jin R, Hiemstra C, Zhong Z, Feijen J (2007) Enzymemediated fast in situ formation of hydrogels from dextrantyramine conjugates. Biomaterials 28: 2791-2800.

Jin R, Moreira Teixeira LS, Dijkstra PJ, Zhong Z, van Blitterswijk CA, Karperien M, Feijen J (2010) Enzymatically crosslinked dextran-tyramine hydrogels as injectable scaffolds for cartilage tissue engineering. Tissue Eng A 16: 2429-2440.

Jones DG, Peterson L (2006) Autologous chondrocyte implantation. J Bone Joint Surg Am 88: 2502-2520.

Kelm JM, Fussenegger M (2004) Microscale tissue engineering using gravity-enforced cell assembly. Trends Biotechnol 22: 195-202.

Khademhosseini A, Langer R, Borenstein J, Vacanti JP (2006) Microscale technologies for tissue engineering and biology. Proc Natl Acad Sci USA 103: 2480-2487.

Kouri JB, Arguello C, Luna J, Mena R (1998) Use of microscopical techniques in the study of human chondrocytes from osteoarthritic cartilage: an overview. Microsc Res Tech 40: 22-36.

Kuo CK, Li WJ, Mauck RL, Tuan RS (2006) Cartilage tissue engineering: its potential and uses. Curr Opin Rheumatol 18: 64-73.

Lee GM, Paul TA, Slabaugh M, Kelley SS (2000) The incidence of enlarged chondrons in normal and osteoarthritic human cartilage and their relative matrix density. Osteoarthritis Cartilage 8: 44-52.

Lotz MK, Otsuki S, Grogan SP, Sah R, Terkeltaub R, D'Lima D (2010) Cartilage cell clusters. Arthritis Rheum 62: 2206-2218.
Maeda A, Nishida T, Aoyama E, Kubota S, Lyons KM, Kuboki T, Takigawa M (2009) CCN family 2/connective tissue growth factor modulates BMP signalling as a signal conductor, which action regulates the proliferation and differentiation of chondrocytes. J Biochem 145: 207-216.

Martinez I, Polacek M, Bruun JA, Johansen O (2010) Differences in the secretome of cartilage explants and cultured chondrocytes unveiled by SILAC technology. J Orthop Res 28: 1040-1049.

McGlashan SR, Cluett EC, Jensen CG, Poole CA (2008) Primary cilia in osteoarthritic chondrocytes: from chondrons to clusters. Dev Dyn 237: 2013-2020.

Moreira Teixeira LS, Bijl S, Pully VV, Otto C, Jin R, Feijen J, van Blitterswijk CA, Dijkstra PJ, Karperien M (2012) Self-attaching and cell-attracting in-situ forming dextran-tyramine conjugates hydrogels for arthroscopic cartilage repair. Biomaterials 33: 3164-3174.

Penick KJ, Solchaga LA, Welter JF (2005) Highthroughput aggregate culture system to assess the chondrogenic potential of mesenchymal stem cells. Biotechniques 39: 687-691.

Pfander D, Kortje D, Weseloh G, Swoboda B (2001) [Cell proliferation in human arthrotic joint cartilage]. Z Orthop Ihre Grenzgeb 139: 375-381.

Poole AR, Rizkalla G, Ionescu M, Reiner A, Brooks E, Rorabeck C, Bourne R, Bogoch E (1993) Osteoarthritis in the human knee: a dynamic process of cartilage matrix degradation, synthesis and reorganization. Agents Actions Suppl 39: 3-13.

Schumacher BL, Su JL, Lindley KM, Kuettner KE, Cole AA (2002) Horizontally oriented clusters of multiple chondrons in the superficial zone of ankle, but not knee articular cartilage. Anat Rec 266: 241-248.

Song JJ, Aswad R, Kanaan RA, Rico MC, Owen TA, Barbe MF, Safadi FF, Popoff SN (2007) Connective tissue growth factor (CTGF) acts as a downstream mediator of TGF- $\beta 1$ to induce mesenchymal cell condensation. J Cell Physiol 210: 398-410.

Strobel S, Loparic M, Wendt D, Schenk AD, Candrian C, Lindberg RL, Moldovan F, Barbero A, Martin I (2010) Anabolic and catabolic responses of human articular chondrocytes to varying oxygen percentages. Arthritis Res Ther 12: R34.

Szklarczyk D, Franceschini A, Kuhn M, Simonovic M, Roth A, Minguez P, Doerks T, Stark M, Muller J, Bork P, Jensen LJ, von Mering C (2011) The STRING database in 2011: functional interaction networks of proteins, globally integrated and scored. Nucleic Acids Res 39: D561-568.

Vavken P, Samartzis D (2010) Effectiveness of autologous chondrocyte implantation in cartilage repair of the knee: a systematic review of controlled trials. Osteoarthritis Cartilage 18: 857-863.

Wolf F, Candrian C, Wendt D, Farhadi J, Heberer M, Martin I, Barbero A (2008) Cartilage tissue engineering using pre-aggregated human articular chondrocytes. Eur Cell Mater 16: 92-99.

Woodfield TB, Bezemer JM, Pieper JS, van Blitterswijk CA, Riesle J (2002) Scaffolds for tissue engineering of cartilage. Crit Rev Eukaryot Gene Expr 12: 209-236. 